\title{
AN EFFECT OF X RAYS ON THE LINKAGE OF MENDELIAN CHARACTERS IN THE FIRST CHROMOSOME OF DROSOPHILA
}

\author{
JAMES W. MAVOR \\ Union College, Schenectady, New York
}

Received March 18, 1923

TABLE OF CONTENTS



INTRODUCTION

In the course of experiments designed to test the effects of $\mathrm{X}$ rays in causing non-disjunction of the sex chromosomes of Drosophila (MAvor $1921 \mathrm{a}, \mathrm{b}, 1922,1923)$ opportunity was given also to test for an effect of $\mathrm{X}$ rays on crossing over. Crossing over in the sex chromosomes of Drosophila has been studied in great detail by MORGAN and BRIDGes (1916) and others. The very extensive data collected by these investigators have been used to construct chromosome maps and to develop subsidiary theories of the mechanism of crossing over. BRIDGES (1915) has shown that the amount of crossing over in the second chromosome decreases with the age of the fly. Plougr (1917) found that temperatures above and below the normal breeding temperature $\left(22^{\circ} \mathrm{C}\right)$ caused an increase in the amount of crossing over in the second chromosome. Further investigation of the temperature effect by the same writer (PLOUGH 1921) showed that crossing over in a region of the third chromosome was increased by exposure to a temperature above normal. He found, however, "that a temperature of $31.5^{\circ} \mathrm{C}$ causes little or no effect on crossing over in any part of the sex chromosome, nor is there any significant variation with the age of the female." DetLeFsen and Roberts (1921), using the recessive characters white eye and miniature wing (the same as those used in the present investigation), have found that crossing over in the sex chromosome can be decreased by breeding from individuals showing a low crossover value. They were however unable to increase the crossover value by selection in the reverse direction. 
When a white-eyed, long-winged female is crossed with an eosin-eyed, miniature-winged male, the daughters are all heterozygous and may be represented by the formula $\frac{w M}{w^{e} m}$, indicating that one of the $\mathrm{X}$ chromosomes carries the determiners for white eye color $(w)$ and long wings $(M)$, while the other carries the determiners for eosin eye color $\left(w^{e}\right)$ and miniature wings $(m)$. If such a heterozygous female is bred, she will have four kinds of regular sons irrespective of the male with which she is crossed, since the regular sons obtain their $\mathrm{X}$ chromosomes only from their mother. In two of the kinds of sons the characters will appear as they entered in the original cross, i.e., one kind will be white-eyed and long-winged and the other eosin-eyed and miniature-winged; these make up the noncrossover classes. In the other two kinds, on the other hand, the characters will be interchanged, i.e., one kind will be white-eyed and miniaturewinged and the other eosin-eyed and long-winged; these make up the crossover classes. It is usual in work on crossing over to cross the heterozygous individual,--in this case a female,-with a double recessive, which in this case would be a white-eyed, miniature-winged male, so that the daughters also show the four classes described above. The experiments to be described were designed primarily to test for non-disjunction and for that reason the heterozygous females were mated to males with the dominant character, red eyes, so that the exceptional sons and daughters could be recognized. This did not of course affect the characters of the regular sons and the data presented give the crossover values obtained from counts of these. No attempt has been made to correct the data for double crossing over.

Effects due to differences in the viability of the classes have not been entirely eliminated. To do this would involve repeating the experiment using for the control and X-rayed females, flies of the formula $\frac{w m}{w^{e} M}$. However, it will be noted that each of the mutations occurs in one of the crossover and one of the non-crossover classes, and further, that in neither the offspring of the control nor of the X-rayed females is there a significant difference between the classes of crossovers or between the classes of non-crossovers.

The evidence for the effect of $\mathrm{X}$ rays on crossing over rests entirely on a comparison of the crossover values for the $\mathrm{X}$-rayed and control females, as must be the case in any investigation of the effect of an external agent. In the experiments, both the X-rayed and the control females were sisters which emerged at approximately the same time, were kept at the 
same temperature $\left(23^{\circ} \mathrm{C}\right)$ in bottles of the same size containing banana agar made at the same time from the same bananas and sprayed with yeast from the same cake. On account of not being corrected for double crossing over the crossover values given in the tables for the controls are lower than those usually given for the characters concerned.

\section{X-RAY EXPERIMENTS}

A brief statement may be made concerning the X-ray technique and the method of recording the dose. A water-cooled Coolidge X-ray tube with tungsten target was used. It was operated at 50,000 volts, root mean square, alternating current. The number of milliamperes passing through the tube, the distance from the target and the time of treatment were different in the different experiments. The following method has been used to express the doses in comparable form. A dose in which the number of milliamperes was 1 , the distance from the target $10 \mathrm{~cm}$ and the time 1 minute, was taken as a unit and called D. Any dose at 50,000 volts is therefore expressed by $\frac{\text { number of milliamperes } \times \text { time in minutes }}{\text { (distance in decimeters) }^{2}}$.

The first experiments in which the effect of $\mathrm{X}$ rays on crossing over was tested were those of the third series of $\mathrm{X}$-ray experiments. The females, $\frac{w M}{w^{e} m}$, were obtained virgin by isolating pupae in test tubes containing banana agar. The $\mathrm{X}$-ray dose was given to the females before mating. This dose, which was always at 50,000 volts, varied in the third series of experiments from 21 to $49 \mathrm{D}$. The females were mated, immediately after being $\mathrm{X}$-rayed, to wild-type males. The pairs, both X-rayed and control, were allowed to remain in the first bottles for six days and in the second bottles for eight days. The $F_{1}$ were counted in the bottles until eighteen days after the parents were placed in the bottles, the temperature of the incubator being maintained between $22.7^{\circ}$ and $24.4^{\circ} \mathrm{C}$.

The results of the counts for the two sets of bottles and the different doses of $X$ rays are given in table 1 which also gives the differences between the number of crossovers in the $F_{1}$ of the $\mathrm{X}$-rayed and the mean number to be expected from the controls divided by the probable error of the difference. ${ }^{1}$ This table shows that there is no significant change in the crossover value in the first bottles of the X-rayed. This is true for the totals corresponding to the different doses of $\mathrm{X}$ rays and it is also true for the total of all the experiments in the series $\left(\frac{\text { Diff. }}{\text { P.E.diff. }}=.87\right)$.

1 For the formula used in making these calculations see K. PEArson (1907). 





On the other hand, in the case of the second bottles there is a significant decrease in the crossover value wherever a sufficient number of $F_{1}$ were obtained from the $\mathrm{X}$-rayed females to give a significant result, i.e., after doses of 21 to 23,26 to 29,35 to $37 \mathrm{D}$. After doses of 38 to 43 and 44 to $49 \mathrm{D}$ the number of $\mathrm{F}_{1}$ obtained from the $\mathrm{X}$-rayed females was so small that little significance can be attached to the crossover values obtained. The total for all the experiments of the series (dose 21 to 49) shows also a significant decrease in the crossover value both when compared with the control value $\left(\frac{\text { Diff. }}{{\mathrm{P} . \mathrm{E} \cdot \text { diff. }}}=14.97\right)$ and when compared with the crossover value obtained for the same pairs in the first bottles ( $\left.\frac{\text { Diff. }}{\text { P. E. } \text { diff. }_{\text {. }}}=9.31\right)$. The table also indicates that the crossover values in the second bottles decrease as the X-ray dose increases, as may be seen by comparing the crossover values for doses of 21 to $29 \mathrm{D}$ and 35 to $49 \mathrm{D}$, when the difference is found to be 4.8 times the probable error of the difference.

In the fourth series of experiments the parent flies were of the formula $\frac{w M}{w^{e} m}$ and the experiments were conducted in exactly the same way except for three important differences. The females used in the experiments, both for the control and X-rayed, were the offspring of one whiteeyed female. The X-ray dose in this series was that found in the third series to be the most suitable for modifying the crossover value, namely, 35 to $38 \mathrm{D}$. The time of treatment was varied between wide limits. Group I, which received a dose of $35 \mathrm{D}$, was treated for 3 minutes and 17 seconds; group II, which received $38 \mathrm{D}$ was treated for 2 hours and 15 minutes; and group III, which received $36 \mathrm{D}$, was treated for 20 hours and 20 minutes. Group III, therefore, while receiving only 2.9 percent more radiant energy, $\frac{\text { (milliamperes } \times \text { time) }}{\text { distance }^{2}}$, than group I, received that energy during a time which was 372 times as long (20 hours and 20 minutes) as the time during which the flies of group I received their X-ray dose. The X-rayed and control females were transferred to new bottles every three days, so that the first and second bottles of the fourth series of experiments together correspond to the first bottles of the third series, and the third and fourth bottles of the fourth series to the second bottles of the third series. The offspring were counted until eighteen days after the parents were placed in the bottles. 


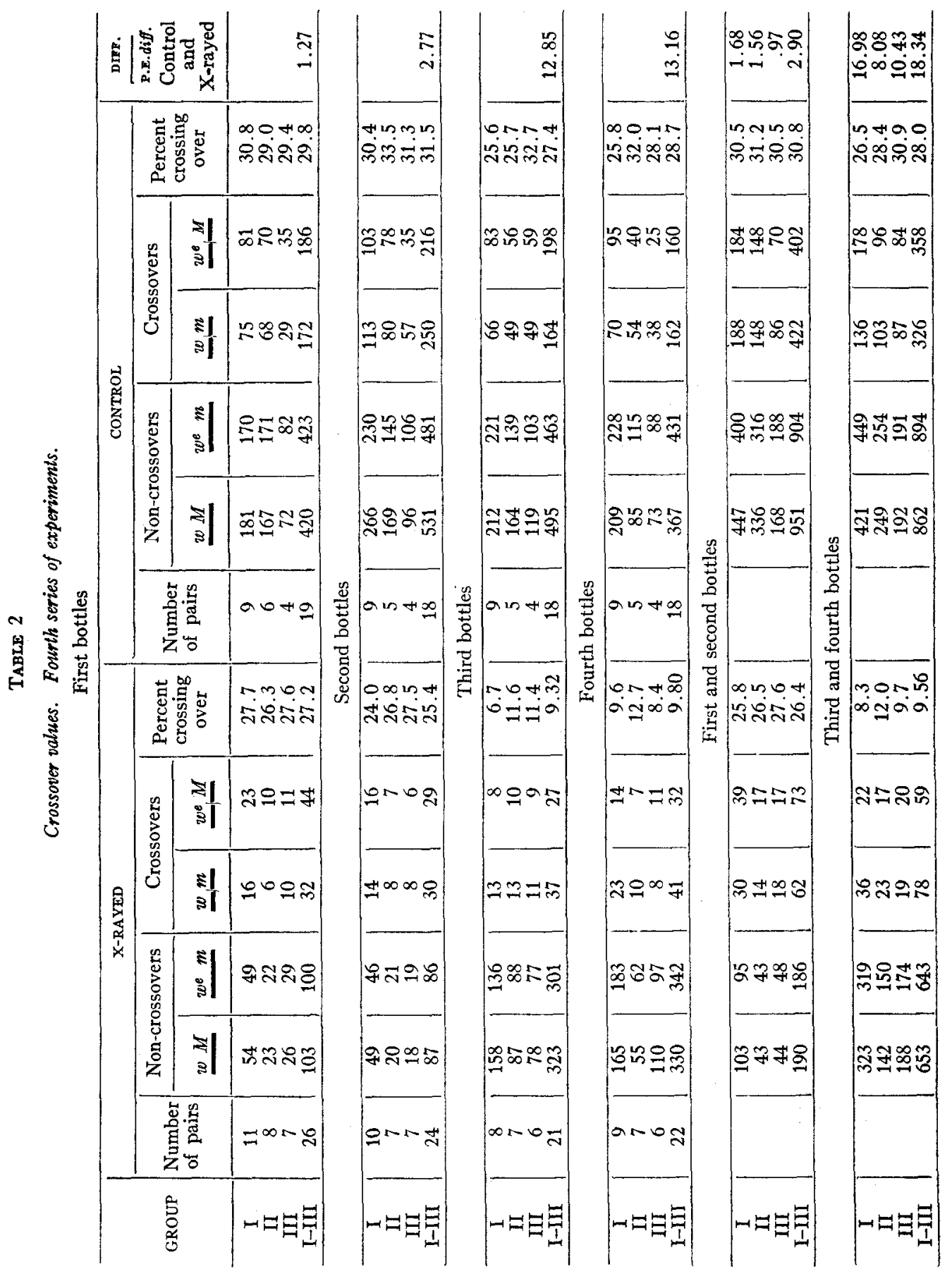




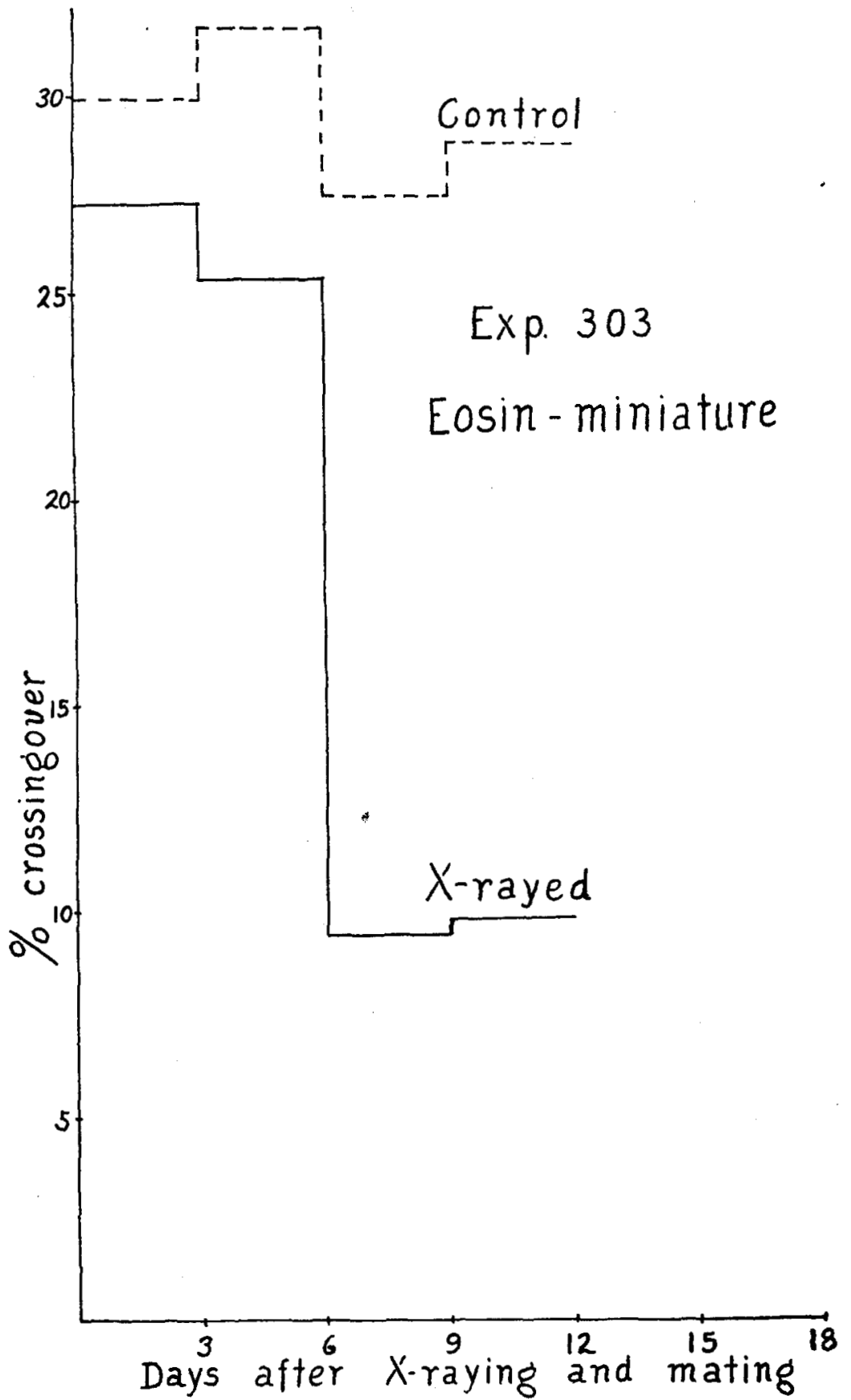

FIGURE 1.-Graph showing percent of crossing over in the control and X-rayed females of experiment 303 , fourth series.

GeNETICs 8: J1 1923 
The results of the fourth series of experiments are shown in table 2, and graphically in figures 1 and 2 . We find here, as in the third series of experiments, that there is no significant difference in the crossover values obtained from the first two bottles (eggs laid during the first six days) of the $\mathrm{X}$-rayed and control flies. For the three groups taken together the difference between the crossover values found for the $\mathrm{X}$-rayed and the mean expected from the controls, divided by the probable error of the difference is for the first bottles (eggs laid during the first three days) 1.27 and for the second bottles (eggs laid during the second three days) 2.77, showing that

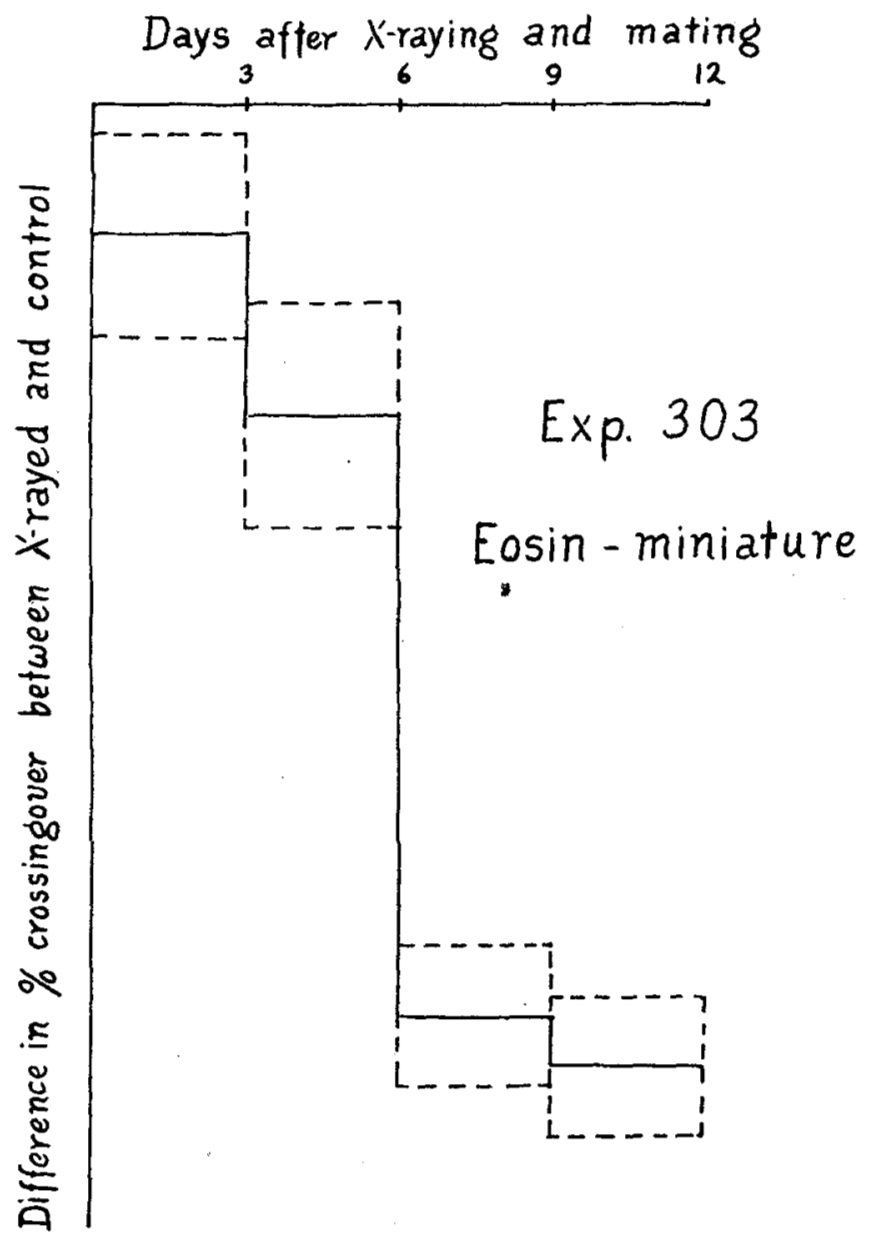

FIGURE 2.-Graph showing the difference between the percent of crossing over in the control and $X$-rayed females of experiment 303 , the difference being indicated by the continuous lines, and the probable error of that difference by the broken lines. The vertical scale has been omitted but is the same as in figure 1 . 
these differences are probably without significance. In the case of the third and fourth bottles the difference in the crossover values obtained for the $\mathrm{X}$-rayed and control females is clearly seen. For all three groups taken together we find in the third bottles a crossover value of 9.32 percent for the X-rayed females as compared with a crossover value of 27.4 percent for the control females, the difference being in this case 12.85 times the probable error. In the fourth bottles for the same three groups we find a crossover value of 9.80 percent for the $\mathrm{X}$-rayed females and 28.7 percent for the controls, the difference in this case being 13.16 times the probable error. It is thus apparent that the effect of the $\mathrm{X}$ rays has been to decrease the crossover value in both the third and fourth bottles. The effect of the $\mathrm{X}$ rays thus extends over a period of approximately six days. This is true of group I taken alone, as is shown by the difference between the crossover values for the control and the $\mathrm{X}$-rayed females, being, in the case of the third bottles, 9.62 and in the case of the fourth bottles, 9.16 times the probable error of the difference. We therefore have the somewhat surprising result that an X-ray treatment lasting only 3 minutes and 17 seconds produces an effect on crossing over which is evident for six days, and further that the effect of $\mathrm{X}$ rays on crossing over depends within wide limits only on the total radiant energy received by the flies and not on the duration of the treatment. It is also to be noted that in each of the three groups the difference between the crossover value found for the first two bottles of the X-rayed females and that found for the last two bottles of the same females, is significant, the differences being $8.37,4.66$, $5.96,11.07$, times the probable error of the difference in groups I, II, III and I to III, respectively. The table for the fourth series shows more clearly what is also apparent in the table for the third series, namely, that the crossover value becomes modified by the $\mathrm{X}$ rays at about the same time as the flies recover their fertility after the partial sterility produced during the first six days by the X-ray treatment. Stated in another way, during the time that the $\mathrm{X}$ rays produce an alteration in crossing. over in the eggs, few eggs are fatally injured by the $\mathrm{X}$ rays. It is unfortunate that the series of experiments was terminated in the fourth bottles and that the control and X-rayed flies were not transferred to fifth and sixth bottles.

The results of the fourth series confirm those of the third series. Since the data are comparable, the females having had the same genetic constitutions, it is possible to add the numbers of non-crossovers and crossovers in the first bottles of the third series to the corresponding numbers for the first and second bottles in the fourth series and similarly to add the 
numbers of non-crossovers and crossovers in second bottles of the third series and the third and fourth bottles of the fourth series. When this is done we find that the difference between the crossover values of the control and X-rayed females for eggs laid during the first six days is 2.03 times the probable error and that the difference between the crossover values of the control and $\mathrm{X}$-rayed females for eggs laid during the second six days of egg-laying is 28.37 times the probable error of the difference. The evidence for $\mathrm{X}$ rays having an effect on the crossover value is therefore very strong.

Daughters of the X-rayed and control females were bred to determine if the decrease in the crossover value produced by the $\mathrm{X}$ rays was inherited. The data which are somewhat meager are given in table 3 . There is no evidence of inheritance of the decreased crossover value in either the first or second bottles of the daughters.

TABLE 3

Crossing over in X-rayed females and their daughters.

\begin{tabular}{|c|c|c|c|c|c|c|c|c|c|}
\hline & & \multicolumn{2}{|c|}{ X-R.AYED } & \multirow{2}{*}{$\begin{array}{l}\text { PERCENT } \\
\text { CROSSING } \\
\text { OVER }\end{array}$} & \multicolumn{4}{|c|}{ CONTROL } & \multirow[b]{2}{*}{$\begin{array}{c}\text { PERCENT } \\
\text { CROSSING } \\
\text { OVER }\end{array}$} \\
\hline & & $\begin{array}{l}\text { Non- } \\
\text { cross- } \\
\text { overs }\end{array}$ & $\begin{array}{l}\text { Cross- } \\
\text { overs }\end{array}$ & & & & $\begin{array}{l}\text { Non- } \\
\text { cross- } \\
\text { overs }\end{array}$ & $\begin{array}{l}\text { Cross- } \\
\text { overs }\end{array}$ & \\
\hline $\begin{array}{l}\text { X-rayed } \\
\text { females } \\
\text { 3rd bottles }\end{array}$ & $\begin{array}{l}A^{\prime} \\
B^{\prime} \\
C^{\prime}\end{array}$ & $\begin{array}{l}35 \\
29 \\
29\end{array}$ & $\begin{array}{l}3 \\
2 \\
3\end{array}$ & $\begin{array}{l}7.9 \\
6.5 \\
9.4\end{array}$ & $\begin{array}{l}\text { Control } \\
\text { females } \\
\text { 3rd bottles }\end{array}$ & $\begin{array}{l}\text { A } \\
B \\
C\end{array}$ & $\begin{array}{l}76 \\
64 \\
67\end{array}$ & $\begin{array}{l}22 \\
20 \\
24\end{array}$ & $\begin{array}{l}22.3 \\
23.6 \\
26.4\end{array}$ \\
\hline $\begin{array}{l}\text { Daughters } \\
\text { of X-rayed } \\
\text { 1st bottles }\end{array}$ & $\begin{array}{l}\mathrm{A}^{\prime} \\
\mathrm{B}^{\prime} \\
\mathrm{C}^{\prime}\end{array}$ & $\begin{array}{r}82 \\
116 \\
54\end{array}$ & $\begin{array}{l}40 \\
39 \\
34\end{array}$ & $\begin{array}{l}32.8 \\
25.2 \\
38.7\end{array}$ & $\begin{array}{l}\text { Daughters } \\
\text { of control } \\
\text { 1st bottles }\end{array}$ & $\begin{array}{l}\text { A } \\
\text { B } \\
\text { C }\end{array}$ & $\begin{array}{l}54 \\
48 \\
39\end{array}$ & $\begin{array}{l}24 \\
41 \\
13\end{array}$ & $\begin{array}{l}30.8 \\
45.2 \\
25.0\end{array}$ \\
\hline $\begin{array}{l}\text { Daughters } \\
\text { of X-rayed } \\
\text { 2nd bottles }\end{array}$ & $\begin{array}{l}\mathrm{A}^{\prime} \\
\mathrm{B}^{\prime} \\
\mathrm{C}^{\prime}\end{array}$ & $\begin{array}{l}65 \\
25 \\
18\end{array}$ & $\begin{array}{l}19 \\
13 \\
20\end{array}$ & $\begin{array}{l}22.6 \\
34.2 \\
52.7\end{array}$ & $\begin{array}{l}\text { Daughters } \\
\text { of control } \\
\text { 2nd bottles }\end{array}$ & $\begin{array}{l}\mathrm{A} \\
\mathrm{B} \\
\mathrm{C}\end{array}$ & $\begin{array}{l}29 \\
27 \\
36\end{array}$ & $\begin{array}{l}20 \\
17 \\
17\end{array}$ & $\begin{array}{l}40.8 \\
38.6 \\
32.1\end{array}$ \\
\hline
\end{tabular}

DISCUSSION

Were it not clear in the case of the sex chromosome that there is no significant variation in the crossover values with age, it might be objected that the differences in crossover values shown in the data from the experiments could be due to an accelerated development of the germ cells of the $\mathrm{X}$-rayed females, since $\mathrm{X}$ rays are known to cause acceleration. This 
would mean that the offspring produced by the X-rayed females in the second period when the decreased crossover values were obtained, really corresponded to the offspring produced by older flies than those in the controls. It is of course possible that the development of the germ cells, in the oögonial divisions and maturation stages, is accelerated by the $\mathrm{X}$ rays, but such an acceleration would not explain the differences in the crossover values obtained.

In the experiments described no account has been taken of double crossing over. Since the characters used involved only two loci this was not possible. It is therefore possible that the decrease in the crossover value between eosin and miniature may really be due to an increase in double crossing over. Experiments are already in progress using a number of loci in the $\mathrm{X}$ chromosome and it is expected that they will give the answer to this question. A difference in the viability of the crossover and non-crossover class accentuated by the $\mathrm{X}$ rays may be considered as an explanation of the differences in crossover values obtained. In other words the decrease in the crossover values may be due to a difference in susceptibility between the crossover and non-crossover classes. Since the females were submitted to $\mathrm{X}$ rays before mating this would mean that there was a difference in susceptibility between the crossover and non-crossover eggs before fertilization, i.e., before development started-a rather unlikely condition. This suggests another explanation which may be advanced-that the egg is more susceptible to $X$ rays at the time when crossing over is taking place, so that their number is reduced and in consequence the numbers of flies in the crossover classes. In this connection it is to be noted that the decrease in the crossover values was produced by a dose of $X$ rays which lasted 3 minutes and 17 seconds and that the crossover values were reduced from 25.8 percent to 8.3 percent in the eggs laid during six days. Further, practically the same result is obtained if the treatment lasts for 20 hours and 20 minutes. If then the $\mathrm{X}$ rays were effective only during the process of crossing over, that process would have to be one of long duration (approaching six days). The results might of course be obtained if the process of crossing over occurred rythmically in the fly, with long intervals, but we know of no facts to support this.

The evidence therefore tends to show that the $\mathrm{X}$ rays do not directly affect the process of crossing over but that they produce in the chromosomes or the nucleus generally a condition which inhibits crossing over (or increases double crossing over). If, however, the $\mathrm{X}$ rays had a direct 
effect on the constitution of the chromosomes one would expect such an effect to be inherited, a result not obtained in the experiments.

From the point of view of the biological effects of $\mathrm{X}$ rays two of the results obtained in these experiments are of considerable importance. So far as at present known $\mathrm{X}$ rays are the only physical or chemical agents which affect crossing over in the $\mathrm{X}$ chromosome of Drosophila. The effect produced by the $\mathrm{X}$ rays is independent of the duration of the $\mathrm{X}$-ray treatment over a wide range (factor of 372). This latter result is the same as that obtained when $\mathrm{X}$ rays are allowed to act directly on a photographic plate. ${ }^{2}$

\section{CONCLUSIONS}

1. It has been shown that $\mathrm{X}$ rays cause a decrease in the crossover value between eosin and miniature.

2. The decrease in the crossover value is probably not inherited.

3. An X-ray dose lasting for 3 minutes and 17 seconds produces an effect which is apparent over a period of six days.

4. This suggests that the decrease in the crossover value produced by the $\mathrm{X}$ rays is not due to a direct effect of the $\mathrm{X}$ rays on the crossing-over process.

\section{LITERATURE CITED}

BRIDGES, C. B., 1915 A linkage variation in Drosophila. Jour. Exper. Zoöl. 19: 1-21.

DetLefsen, J. A., and Roberts, E., 1921 Studies on crossing over. I. The effect of selection on crossover values. Jour. Exper. Zoöl. 32: 333-354.

Mavor, J. W., 1921 a On the elimination of the X chromosome from the egg of Drosophila melanogaster by $\mathrm{X}$ rays. Proc. Soc. Exper. Biol. Med. 18: 301-302.

$1921 \mathrm{~b}$ On the elimination of the $\mathrm{X}$ chromosome from the egg of Drosophila melanogaster by $X$ rays. Science, N. S. 54: 277-279.

1922 The production of non-disjunction by $X$ rays. Science N. S. 55: 295-297.

$1923 X$ rays and the sex chromosomes. Science, N. S. 57: 503-504.

Morgan, T. H., and Bridgrs, C. B., 1916 Sex-linked inheritance in Drosophila. Carnegie Inst. Washington, Publ. 237, 87 pp., 2 pl.

Pearson, K., 1907 On the influence of past experience on future expectation. Philos. Mag. 6 ser. 13: $365-378$.

Plovgr, H. H., 1917 The effect of temperature on crossing over in Drosophila. Jour. Exp. Zoöl. 24: 147-209.

1921 Further studies on the effect of temperature on crossing over. Jour. Exp. Zoöl. 32: 187-202.

${ }^{2}$ Dr. Coolmge tells me that in experiments carried on in the Research Laboratory of the General Electric Company no difference could be observed in the effect on photographic plates exposed to intensities represented by $6, .6, .06, .006$ milliamperes, when the target distance and the product, milliamperes $\times$ time, was kept constant. In this case there was a factor of 1000 . 